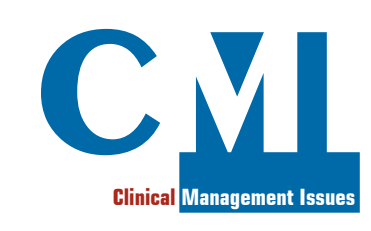

\title{
Acknowledgement to Reviewers (January 2020 - December 2020)
}

The editorial staff of Clinical Management Issues (CMI) would like to thank all the reviewers who, with their support and their active cooperation, have contributed to improving the scientific rigor, precision and accuracy of the contents.

- Riccardo Asteggiano

- Stefania Chetcuti Zammit

- Rosario Ciliento

- Johnny Mahlangu

- Pier Mannuccio Mannucci

- Adrian Meehan

- Raffaele Pezzilli

- Aurel Popa-Wagner

- Marco Sforza

- Pieter van der Bijl

- Umberto Vitolo 